\title{
Equações diferenciais parciais de evolução e aplicações.
}

\author{
Pedro L. T. Neves*, Bianca M. R. Calsavara
}

\section{Resumo}

Neste projeto são estudadas equações diferenciais parciais de evolução de segunda ordem, mais especificamente as equações do calor e da onda. Para estas equações são analisadas existência, unicidade e algumas propriedades de solução para os casos unidimensional e n-dimensional. Também são vistas algumas aplicações destas equações.

\section{Palavras-chave: \\ Equações diferenciais parciais de evolução, Equação da onda, Equação do calor.}

\section{Introdução}

O projeto possui como objetivo o estudo das equações do calor e da onda. Estas são equações diferenciais parciais que descrevem, por exemplo, a difusão do calor em sólidos homogêneos e a propagação de ondas físicas, respectivamente.

Para a equação da onda e do calor unidimensionais foram obtidos resultados de existência e unicidade de solução. Para a equação da onda também foram obtidos domínio de dependência e velocidade de propagação finita. E para a equação do calor, um princípio de máximo, a velocidade de propagação infinita e um princípio de regularidade.

$\mathrm{Na}$ parte do projeto dedicada às equações do calor e da onda $n$-dimensionais, foram obtidos resultados análogos aos mencionados acima, porém, utilizando outros métodos.

\section{Resultados e Discussão}

A princípio, foram analisadas as equações do calor e da onda unidimensionais (na variável espacial) e, em seguida, generalizou-se o estudo para mais dimensões.

Para ambos os casos, questões fundamentais, como existência e unicidade de solução, foram abordadas inicialmente. Algumas diferenças e semelhanças entre as soluções destas equações, então, puderam ser observadas, tanto em termos dos métodos que levam às soluções quanto às características destas.

Começando pela equação do calor unidimensional, foi obtida solução da mesma para diferentes condições iniciais e de fronteira utilizando o método de separação de variáveis. Em seguida, foi analisado o caso não homogêneo utilizando o método de variação dos parâmetros. Posteriormente, foram tratados Princípios de Máximo, continuidade de solução em relação aos dados iniciais e unicidade de solução. Além disso, foram vistas aplicações em propagação de calor em uma barra, para várias situações, e variação de temperatura no solo.

Para a equação da onda unidimensional foram considerados problemas de corda vibrante em várias situações, como corda finita, infinita, com extremos fixos ou não, etc., para as quais foram obtidas soluções através do método de separação de variáveis. Propriedades, como energia, harmônicos, e ressonância, também foram analisadas. Finalmente foi obtida a solução da equação da onda unidimensional não homogênea utilizando o método de D'Alembert.

Foi, então, feita a generalização dos dois problemas citados para dimensão $n>1$. No caso da equação do calor n-dimensional homogênea, foi derivada sua solução fundamental e, assim, obtida a solução de um problema de valor inicial (PVI). O princípio de Duhamel foi utilizado para encontrar soluções da equação do calor n-dimensional não homogênea. Para a solução da equação do calor foram obtidas propriedades de regularidade, Princípio de Máximo, obtido pela propriedade do valor médio, e unicidade.

Para a obtenção de solução da equação da onda foi empregado o método das médias esféricas no caso de $n$ ímpar, e o método de descida para $n$ par.

É importante ressaltar aqui a utilidade dos métodos de energia, através dos quais foram obtidos unicidade para ambas as equações, unicidade inversa (backwards uniqueness) para a equação do calor, domínio de dependência e velocidade de propagação finita para a equação da onda.

\section{Conclusão}

Este projeto, através do aprofundamento que dá às equações do calor e da onda, possibilita a descoberta e utilização de diversas ferramentas matemáticas importantes na investigação de equações diferenciais parciais. O trabalho fornece uma visão rica e aprofundada dos métodos utilizados e da teoria matemática que os sustenta, além da contextualização das equações citadas.

\section{Agradecimentos}

Aqui, deixo expressa minha gratidão à Profa. Bianca, por ter me orientado e auxiliado no desenvolvimento deste projeto, que foi de fundamental importância para meu amadurecimento acadêmico. Agradeço à Unicamp por ter possibilitado a realização deste trabalho, motivo pelo qual também deixo meus agradecimentos ao PIBIC e ao PICME. Por fim, gratifico a família e amigos por sua fundamental presença e suporte individual.

1. Evans, L., Partial Differential Equations, American Mathematical Society, 1998.

2. Farlow, S.J., Partial Differential Equations for Scientists and Engineers, Editora Dover, 1993.

3. Figueiredo, D.G. de Análise de Fourier e Equações Diferenciais Parciais, $4^{\mathrm{a}}$ edição, Projeto Euclides, IMPA, Rio de Janeiro, 2005.

4. Guidorizzi, H.L., Cálculo, Vol. 4, 5ª edição, Ed. LTC, 2004. 